\title{
Population demography and global sensitivity analysis of Avicennia marina on the eastern and western coasts of Saudi Arabia
}

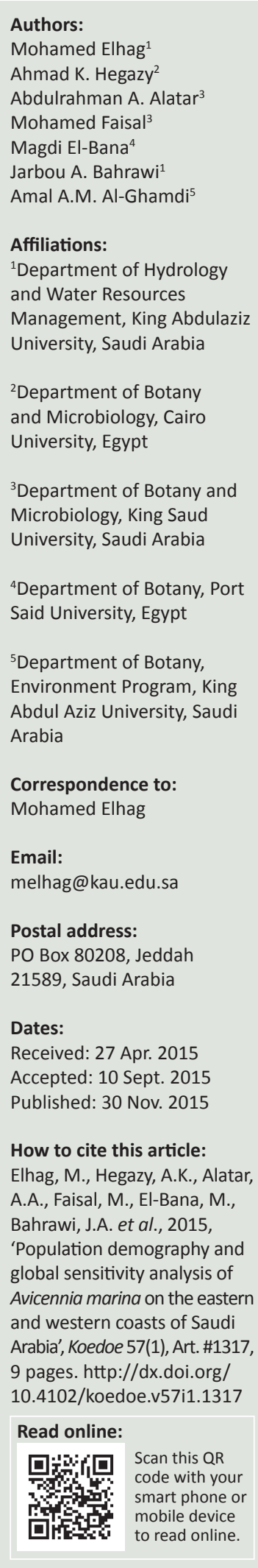

Mangrove ecosystems are one of the habitats that host high environmental diversity at the level of physical, geomorphological and biological features in arid regions. In Saudi Arabia, mangrove ecosystems are heavily threatened by both natural hazards and human pressure. The total estimated area of mangroves in Safwa Al Khurais, Saudi Arabia, is approximately 20000 ha in extent and comprises two species: Avicennia marina and Rhizophora mucronata. They supply detritus to the marine food web and play a significant role in the conservation of biological diversity. The main objective of this study was to analyse the demographic population sensitivity of $A$. marina in two representative sites on the Red Sea and the eastern coast of Saudi Arabia. A sensitivity analysis was used to assess the contributions of the inputs to the total uncertainty in the analysis outcomes. Demographic features affecting mangroves in Saudi Arabia are complex and include various aspects. The phenological phase, tree size, density, cover, number of dead trees and pneumatophore characteristics were considered in this study. A comparative analysis of Gaussian process emulators for performing a global sensitivity analysis was used to conduct a variance-based sensitivity analysis to identify which uncertain inputs drive the output uncertainty. The results showed that the interconnections between different demographic features were predictable, but that the extent of the sensitivity was uncertain. Findings from the current study are anticipated to contribute significantly towards an inclusive mangrove demographic features assessment, and towards the subsequent conservation of mangroves in Saudi Arabia.

Conservation implications: The findings of the current research are discussed in light of the application of sensitivity analyses outputs in the conservation and management of mangrove ecosystems at a national level

\section{Introduction}

Mangroves in Saudi Arabia are found in the form of fragmented populations or thin stands in many tidal areas of the Red Sea and the Arabian Gulf coasts. They consist mainly of two species: Avicennia marina (Forsk.) Vierh. (locally known as Qurum), which is the common species; and Rhizophora mucronata Lam. (locally known as Qundel), which is limited to a few localities. The northerly limit of distribution of A. marina in the Red Sea is Debah, Saudi Arabia, and extends south to the border with Yemen (Khan, Kumar \& Muqtadir 2010; Kumar, Khan \& Muqtadir 2010). In the Arabian Gulf, mangroves are found in very small patches in the north, on Jazeerat Qurma (translated as Mangrove Island) and in Tarut Bay, where they form well-developed stands consisting of A. marina.

Although the mangroves of Saudi Arabia are not as luxurious as those on other tropical shores, they play similarly significant ecological and environmental roles. These locations are nurseries for numerous profitable fish species and they shelter coral reefs by retaining sediment loads from the periodic influx of rain water. Because they grow in very different environments, mangroves are very sensitive to over-exploitation. The degradation of mangrove ecosystems has occurred in various parts of the region, due to excessive browsing by camels, overcutting, impeding rainwater from draining through valleys, pollution, and coastal construction (Mandura 1997; Mandura \& Khafaji 1993).

Human activities such as coastal urbanisation and related wastewater management problems, industrialisation and related emissions, chemical pollutants, fishing activities and aquaculture development, tourism and the consequent increase of pressures on coastal resources are some of the main stresses introduced by humankind on coastal ecosystems (Hegazy 1998; Kumar et al. 2010).

Copyright: @ 2015. The Authors. Licensee: AOSIS OpenJournals. This work is licensed under the Creative Commons Attribution License. 
Global Sensitivity Analysis (GSA) methods assign the output inconsistency to the inconsistency of the input parameters when they fluctuate over their entire uncertainty dimension (Petropoulos et al. 2009). The sensitivity of input parameters is fundamentally based on the generation of samples dispersed across the parameter dimension of interest. Extensive scholarly work of the obtainable GSA approaches and their applications is reported, for example, Saltelli, Chan and Scott (2000), Saltelli (2002), and Saltelli et al. (2004).

Global Sensitivity Analysis is an influential method due to its capability to assimilate the influence of the input parameters over their whole range of inconsistency (Saltelli, Tarantola \& Chan 1999). Global Sensitivity Analysis techniques are able to deliver quantitative assessments not only of the most sensitive model inputs, but also of the interactions of the model input parameters (Schwieger 2004). This yields measureable evidence of the degree of difficulty of the model input-output interactions (Petropoulos et al. 2009).
The aim of this study is to analyse the uncertainty of the survival of $A$. marina based on the demographic features of five populations, located in the Red Sea and the Arabian Gulf of Saudi Arabia. This is useful as a guiding tool for the conservation and sustainable use of mangrove ecosystems in the region.

\section{Materials and methods}

\section{Study area}

Five sites were identified for this study (Figure 1). Two sites are located on the Red Sea coast: Al Mudhaylif (19³0'76.1" N, 40 $56^{\prime} 45.6^{\prime \prime} \mathrm{E}$ ) is located north of Al Qunfudhah city, and Usfan $\left(21^{\circ} 59^{\prime} 18.1^{\prime \prime} \mathrm{N}, 39^{\circ} 00^{\prime} 42.0^{\prime \prime} \mathrm{E}\right)$ is located north of Jiddah city. The remaining three sites are located in the Arabian Gulf: Sehat $\left(26^{\circ} 30^{\prime} 12.8^{\prime \prime} \mathrm{N}, 50^{\circ} 02^{\prime} 35.0^{\prime \prime} \mathrm{E}\right)$ and Safwa Al Khurais (26 39'43.8" $\left.\mathrm{N}, 49^{\circ} 59^{\prime} 15.8^{\prime \prime} \mathrm{E}\right)$ are located in Tarut Bay, and Qurum Island $\left(27^{\circ} 07^{\prime} 56.4^{\prime \prime} \mathrm{N}, 4^{\circ} 29^{\prime} 13.0^{\prime \prime} \mathrm{E}\right)$ is located north of Al Jubail city.

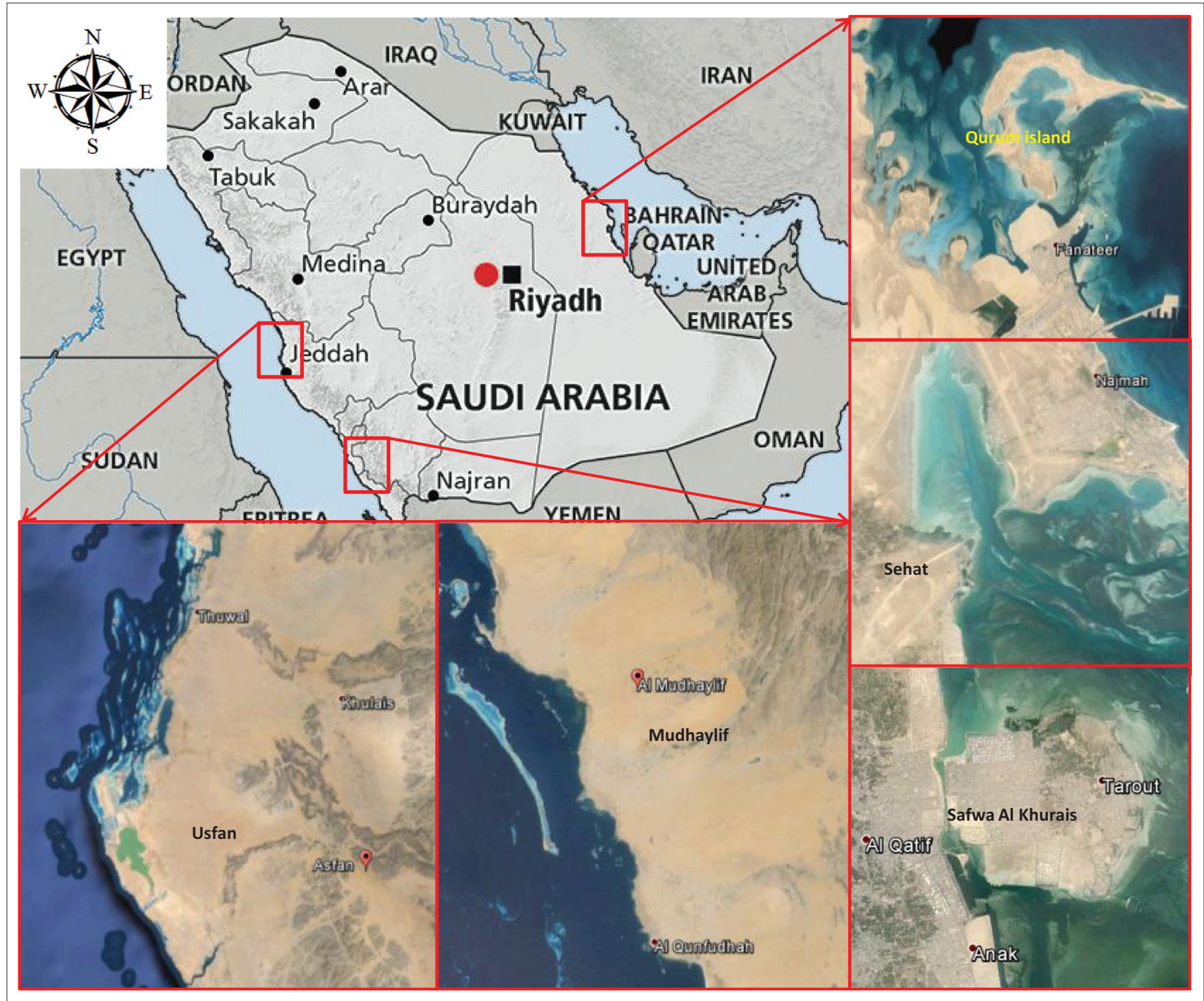

Source: Google Earth

FIGURE 1: The location of the five study sites in the Red Sea (Usfan and Al Mudhaylif) and the Arabian Gulf (Qurum Island, Sehat and Safwa Al Khurais). 


\section{Plant populations}

Measurements of the population characteristics of A. marina were recorded in the five study sites. Plant density was estimated as the number of individuals per $100 \mathrm{~m}^{2}$ for seedlings and adult individuals. The number of dead or partially dead trees was counted. Plant cover was measured by the line intercept method. The density of respiratory roots (pneumatophores) was estimated by counting the number of roots per $\mathrm{m}^{2}$.

\section{Basics of variance-based sensitivity analysis}

Sensitivity analysis approaches are categorised according to the outcome of the related sensitivity procedures into local or global methods, and methods that depend on or are independent of the model characteristics (Schwieger 2004).

\section{The concept of Global Sensitivity Analysis}

Consistent with Saltelli et al. (2000), GSA is the study of the relationship between the input and output of a model. In essence, GSA deals with the variation that corresponds to the uncertainties of the input magnitudes. Moreover, input parameters are introduced to the uncertainties of the model parameters and to the overall model structure. The discrepancy of the input parameters results in discrepancies of the output magnitudes. The interconnections between speckled input and output are measured by various sensitivity measures that are the basis for model validation and optimisation (Schwieger 2004).

The broad practice of sensitivity analysis is shown in Figure 2. Global sensitivity analysis emphasises the variance-based techniques to quantitatively estimate the global variances of the outputs and to investigate the independent sensitivity of the input measures.

\section{Global Sensitivity Analysis procedures}

Based on the Monte Carlo methods, sensitivity analysis methods include regression and correlation analyses as well as the analysis of the rank of the transformed data. The general procedure to estimate global sensitivity measures is based on the following equations:

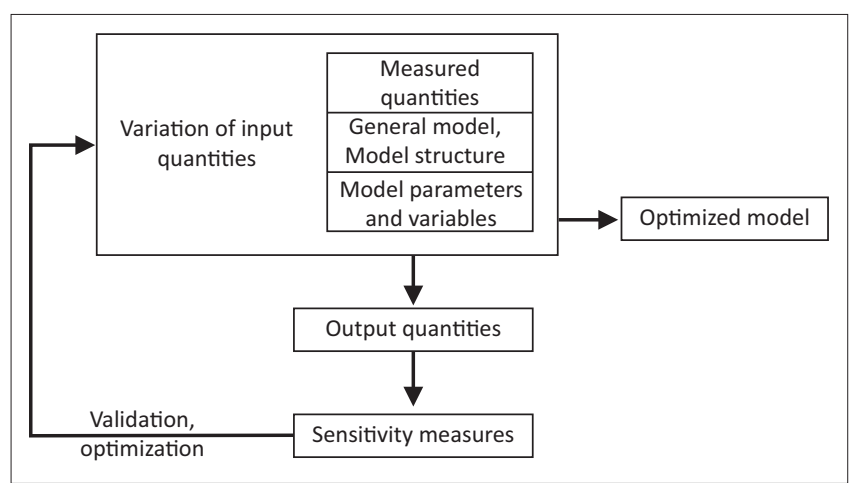

Source: Schwieger, V., 2004, 'Variance-based sensitivity analysis for model evaluation in engineering surveys', INGEO 2004 and FIG Regional Central and Eastern European Conference on Engineering Surveying, Bratislava, Slovakia, November 11-13, 2004

FIGURE 2: The general procedure for a sensitivity analysis.
$S_{i}=\frac{\sigma_{E}^{2}\left(Y / X_{i}\right)}{\sigma_{Y}^{2}}$

Where:
$\sigma_{E}^{2}\left(Y / X_{i}\right)$
is the conditional variance, and
$\sigma_{Y}^{2}$
is the unconditional variance.

For non-correlated input additive models:

$\sum_{i=1}^{n} S_{i}=1$

According to Schwieger (2004), this translates to an easy numerical interpretation of the sensitivity indices, because each $S_{i}$ assures a direct measure for the portion of $X_{i}$ on the output variance $\sigma_{Y}^{2}$. For non-additive models, the interactions amongst the input quantities within the model need to be considered. Non-additive models require a comprehensive disintegration of the function $Y$ into summons of increasing order:

$\sum_{i=1}^{n} S_{i}+\sum_{i=1}^{n} \sum_{j=i+1}^{n} S_{i, j}+\sum_{i=1}^{n} \sum_{j=i+1}^{n}$

$\sum_{k=j+1}^{n} S_{i, j, k}+\cdots+\sum \ldots \ldots S_{i, j, k, \ldots, n}=1$

[Eqn 3]

The terms of higher order are estimated by taking other fixed input quantities into consideration:

$S_{i, j}=\frac{\sigma_{E}^{2}\left(Y / X_{i} X_{j}\right)}{\sigma_{Y}^{2}}-S_{i}-S_{j}$

[Eqn 4]

The estimation of higher order terms leads to the estimation of the total effects $S_{T i}$ with respect to an input quantity $X_{i}$, to be computed as follows:

$S_{T i=} S_{i}+\sum_{i=1}^{n} S_{i}+\sum_{i=1}^{n} \sum_{j=i+1}^{n} S_{i, j}+\sum_{i=1}^{n} \sum_{j=i+1}^{n}$
$\sum_{k=j+1}^{n} S_{i, j, k}+\cdots+\sum \ldots S_{i, j, k, \ldots, n}$ mit $j, k \neq i, j \neq k$

The corresponding total effect is computed as:

$S_{T i}=1-\frac{\sigma_{E}^{2}\left(Y / X_{\sim i}\right)}{\sigma_{Y}^{2}}$

Consistently, a judgement between $S_{i}$ and $S_{T i}$ leads to a conclusion concerning the additivity of models with noncorrelated inputs:

$S_{T i}=S_{i} \quad$ for an additive model, and

$S_{T i}>S_{i} \quad$ for a non-additive model.

\section{Results and discussion}

The results from the sensitivity analysis focus specifically on the decomposition of variance (\%) of the mean total variance in emulator output, where input parameters have 
been assumed to be non-correlated, normally distributed and varying within their whole range.

A sensitivity analysis of mangrove demographic features was carried out on five different mangrove stands: two stands located on the west coast and three located on the east

TABLE 1: Population characteristics and sensitivity analysis in the five study sites.

\begin{tabular}{|c|c|c|c|c|}
\hline Site & $\begin{array}{l}\text { Population } \\
\text { characteristics }\end{array}$ & $\begin{array}{l}\text { Variance } \\
(\%)\end{array}$ & $\begin{array}{l}\text { Standard } \\
\text { deviation }\end{array}$ & $\begin{array}{l}\text { Total } \\
\text { effect }\end{array}$ \\
\hline \multirow[t]{8}{*}{ Usfan } & Density $\left(100 \mathrm{~m}^{2}\right)$ & 8.13 & 0.20 & 8.17 \\
\hline & Cover $(\%)$ & 10.60 & 0.19 & 10.64 \\
\hline & Tree height (m) & 18.34 & 0.25 & 18.4 \\
\hline & Crown diameter $\left(\mathrm{m}^{2}\right)$ & 20.10 & 0.38 & 20.04 \\
\hline & $\begin{array}{l}\text { Number of dead trees } \\
\left(100 \mathrm{~m}^{2}\right)\end{array}$ & 8.18 & 0.38 & 8.21 \\
\hline & $\begin{array}{l}\text { Number of seedlings } \\
\left(100 \mathrm{~m}^{2}\right)\end{array}$ & 1.43 & 0.12 & 1.47 \\
\hline & $\begin{array}{l}\text { Number of respiratory } \\
\text { roots }\left(100 \mathrm{~m}^{2}\right)\end{array}$ & 0.05 & 0.03 & 0.10 \\
\hline & $\begin{array}{l}\text { Average height of } \\
\text { respiratory roots }(\mathrm{m})\end{array}$ & 33.15 & 0.45 & 33.18 \\
\hline \multirow[t]{8}{*}{ Al Mudhaylif } & Density $\left(100 \mathrm{~m}^{2}\right)$ & 7.52 & 0.30 & 7.54 \\
\hline & Cover (\%) & 20.25 & 0.31 & 20.29 \\
\hline & Tree height (m) & 12.41 & 0.32 & 12.45 \\
\hline & Crown diameter $\left(\mathrm{m}^{2}\right)$ & 9.14 & 0.19 & 9.16 \\
\hline & $\begin{array}{l}\text { Number of dead trees } \\
\left(100 \mathrm{~m}^{2}\right)\end{array}$ & 16.79 & 0.34 & 16.83 \\
\hline & $\begin{array}{l}\text { Number of seedlings } \\
\left(100 \mathrm{~m}^{2}\right)\end{array}$ & 10.24 & 0.20 & 1.29 \\
\hline & $\begin{array}{l}\text { Number of respiratory } \\
\text { roots }\left(100 \mathrm{~m}^{2}\right)\end{array}$ & 7.50 & 0.18 & 7.54 \\
\hline & $\begin{array}{l}\text { Average height of } \\
\text { respiratory roots (m) }\end{array}$ & 16.04 & 0.22 & 16.07 \\
\hline \multirow[t]{8}{*}{ Sehat } & Density $\left(100 \mathrm{~m}^{2}\right)$ & 9.56 & 0.18 & 9.56 \\
\hline & Cover (\%) & 15.80 & 0.18 & 15.82 \\
\hline & Tree height (m) & 16.81 & 0.23 & 16.82 \\
\hline & Crown diameter $\left(\mathrm{m}^{2}\right)$ & 8.62 & 0.15 & 8.63 \\
\hline & $\begin{array}{l}\text { Number of dead trees } \\
\left(100 \mathrm{~m}^{2}\right)\end{array}$ & 2.66 & 0.12 & 2.67 \\
\hline & $\begin{array}{l}\text { Number of seedlings } \\
\left(100 \mathrm{~m}^{2}\right)\end{array}$ & 28.64 & 0.21 & 28.65 \\
\hline & $\begin{array}{l}\text { Number of respiratory } \\
\text { roots }\left(100 \mathrm{~m}^{2}\right)\end{array}$ & 14.80 & 0.28 & 14.82 \\
\hline & $\begin{array}{l}\text { Average height of } \\
\text { respiratory roots }(\mathrm{m})\end{array}$ & 3.07 & 0.09 & 3.08 \\
\hline \multirow{8}{*}{$\begin{array}{l}\text { Safwa Al } \\
\text { Khurais }\end{array}$} & Density $\left(100 \mathrm{~m}^{2}\right)$ & 6.57 & 0.27 & 6.61 \\
\hline & Cover (\%) & 14.16 & 0.96 & 14.19 \\
\hline & Tree height (m) & 3.46 & 0.49 & 3.50 \\
\hline & Crown diameter $\left(\mathrm{m}^{2}\right)$ & 9.95 & 0.36 & 9.99 \\
\hline & $\begin{array}{l}\text { Number of dead trees } \\
\left(100 \mathrm{~m}^{2}\right)\end{array}$ & 17.13 & 0.68 & 17.16 \\
\hline & $\begin{array}{l}\text { Number of seedlings } \\
\left(100 \mathrm{~m}^{2}\right)\end{array}$ & 37.46 & 0.74 & 37.50 \\
\hline & $\begin{array}{l}\text { Number of respiratory } \\
\text { roots }\left(100 \mathrm{~m}^{2}\right)\end{array}$ & 7.68 & 0.31 & 7.73 \\
\hline & $\begin{array}{l}\text { Average height of } \\
\text { respiratory roots }(\mathrm{m})\end{array}$ & 3.46 & 0.41 & 3.51 \\
\hline \multirow{8}{*}{$\begin{array}{l}\text { Qurum } \\
\text { Island }\end{array}$} & Density $\left(100 \mathrm{~m}^{2}\right)$ & 23.91 & 1.46 & 23.96 \\
\hline & Cover (\%) & 5.97 & 0.44 & 6.01 \\
\hline & Tree height (m) & 5.06 & 0.21 & 5.25 \\
\hline & Crown diameter $\left(\mathrm{m}^{2}\right)$ & 8.76 & 0.24 & 8.96 \\
\hline & $\begin{array}{l}\text { Number of dead trees } \\
\left(100 \mathrm{~m}^{2}\right)\end{array}$ & 38.45 & 1.41 & 38.51 \\
\hline & $\begin{array}{l}\text { Number of seedlings } \\
\left(100 \mathrm{~m}^{2}\right)\end{array}$ & 16.34 & 1.28 & 16.38 \\
\hline & $\begin{array}{l}\text { Number of respiratory } \\
\text { roots }\left(100 \mathrm{~m}^{2}\right)\end{array}$ & 0.21 & 0.17 & 0.30 \\
\hline & $\begin{array}{l}\text { Average height of } \\
\text { respiratory roots }(m)\end{array}$ & 0.99 & 0.34 & 1.05 \\
\hline
\end{tabular}

Bold, affects the outputs significantly. coast. Both of the western mangrove stands showed a lower sensitivity to the demographic feature number of respiratory roots, where this was observed to be 0.05 and 7.5 , respectively (see Table 1). Conversely, the stands located on the east coast showed a different sensitivity to the demographic features. In Sehat stand, the number of dead trees was the least sensitive mangrove demographic feature. The Safwa Al Khurais stand demonstrated that the average height of respiratory roots was the least sensitive, whilst on Qurum Island the number of respiratory roots was the least sensitive feature. The conclusion drawn from these findings implies interactions or dependency on the rest of the demographic features (Hegazy 1998; Holvoet et al. 2005).

Histogram chart representations of the total effect of the sensitivity analysis demonstrated inter- and intra comparability differences, shown collaterally in Figure 3. In the western region of the study area, the mangrove stand in Usfan is considered to be more stable compared to the $\mathrm{Al}$ Mudhaylif region, where none of the demographic features count for over 33\% individually (the average height of respiratory roots). In the eastern part of the study area, the mangrove stand on Qurum Island is considered to be the most sensitive stand. All of the demographic features were very sensitive and showed a higher uncertainty total variance, except for the average height of respiratory roots. This could be explained by the extensive anthropogenic activities taking places in and around the stand (Kumar et al. 2010).

In the Usfan stand, the results indicated that the most sensitive demographic feature was the average height of respiratory roots, which accounted for $33 \%$. The average height of respiratory roots of mangroves alone accounts for one third of the total effect of the sensitivity analysis. The higher total effect of the average height of respiratory roots explains the lower stability of such demographic features (Elhag 2014; Petropoulos et al. 2009).

The total variance of the sensitivity analysis of mangrove seedlings was calculated to be $0.9 \%$. Such a minor value indicated a robust stability of the mangrove demographic feature in the study area. The next stand on the western side of Saudi Arabia, located at Al Mudhaylif, showed a relative stability compared to the stand located in Usfan (according to the demographic features used in the current study). Both the number of respiratory roots and the number of dead trees ( $8 \%$ for both) were considered to be the least sensitive demographic features according to Petropoulos et al. (2009) and Elhag (2014).

On the eastern side of Saudi Arabia, three different stands of mangroves were considered for sensitivity analysis. Sehatstand is a moderately stable stand, and both the number of dead trees and average height of respiratory roots accounted for $3 \%$ of the total variance. The low total variance percentages represent more stable demographic features, which correspond to environmental variability (Holvoet et al. 2005). 


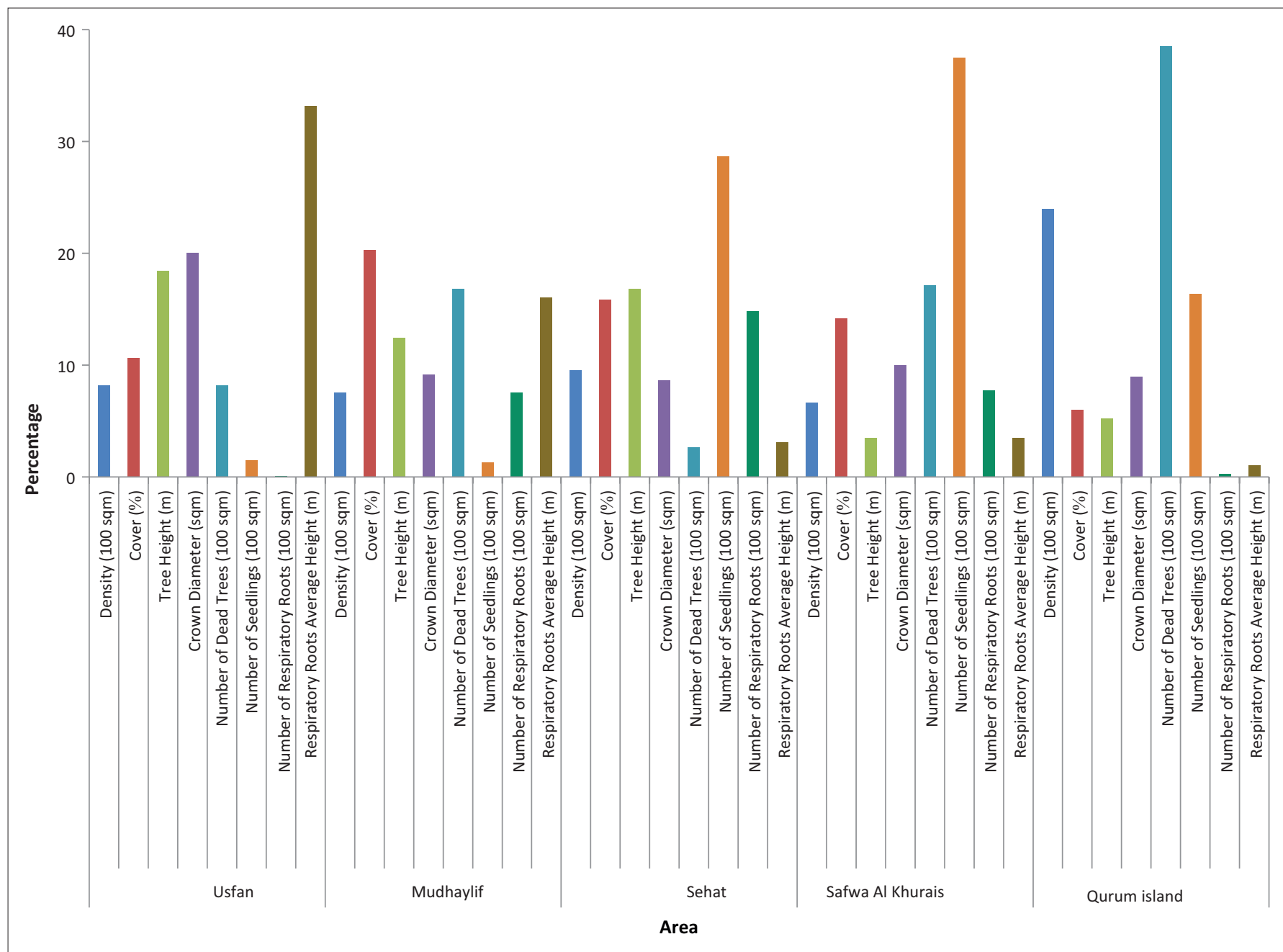

FIGURE 3: The sensitivity analysis total effect (\%).

Within the same geographical region, on the eastern side of the current study, both mangrove stands of Safwa $\mathrm{Al}$ Khurais and Qurum Island were found to be extremely sensitive to environmental impacts. The number of seedlings $(38 \%)$ and tree density of mangroves (39\%) were found to be the most unstable demographic features in Safwa $\mathrm{Al}$ Khurais and on Qurum Island, respectively. The average height and number of respiratory roots were the most stable demographic features in Safwa Al Khurais and on Qurum Island, respectively.

The uncertainty analysis of mangrove demographic features of the Usfan area is shown in Figure 4. There were three mangrove demographic features in Usfan. Density, tree cover and crown diameter showed a higher precision of uncertainty towards higher corresponding demographic values.

The values of mangrove demographic features were proportionally related to the corresponding uncertainty as the main effect, except for the number of seedlings, which was inversely proportionate to its uncertainty value. The number of respiratory roots of mangroves in the Usfan area displayed a steady behaviour of uncertainty levels, with different values of the total number of respiratory roots.
Figure 5 shows that the interactions of the mangrove demographic features of the Al Mudhaylif area were not strong enough to suggest a variance dependency and moderate interactions uncertainty (Elhag 2014; Petropoulos et al. 2009). The mangroves in Al Mudhaylif expressed more uncertainty levels with different demographic features. Uncertainty levels of mangrove demographic features in Al Mudhaylif were higher when compared to Usfan. Higher precisions of uncertainty were expressed in six different demographic features, either in a higher or lower corresponding demographic feature value. All of the demographic features were proportionally related to its corresponding uncertainty as the main effect. Moreover, the number of dead mangroves was inversely proportionate to its uncertainty value (Elhag 2014).

A GSA was also applied to the eastern mangrove stands. Sehat, Safwa Al Khurais and Qurum Island showed that Sehatis was the most stable mangrove stand in the area of investigation (east and west). The mangrove stand at Sehatstand showed good resilience to environmental impacts (Figure 6). The tree cover of mangroves and height of mangroves in Safwa Al Khurais showed sensitive behaviour to environmental impacts (Figure 7), due its higher contributions to the two demographic features of 
the total variance of the GSA. Mangrove trees confined to Qurum Island were considered to be the most degraded mangrove stand because all of the demographic features implemented in the GSA (except the average height of respiratory roots) were remarkably unstable to the surrounding environmental impacts (Figure 8).
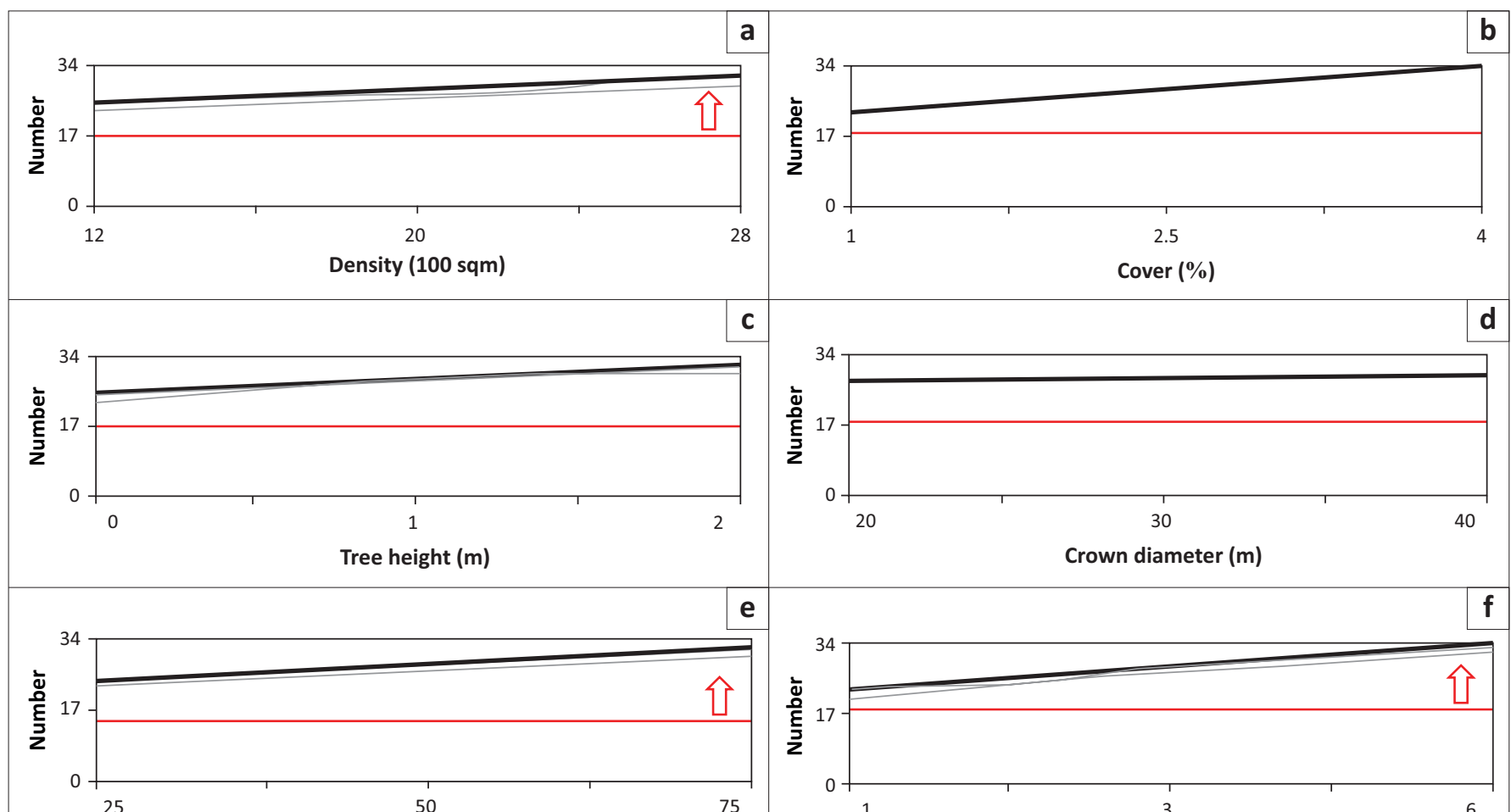

Number of dead trees (100 sqm)
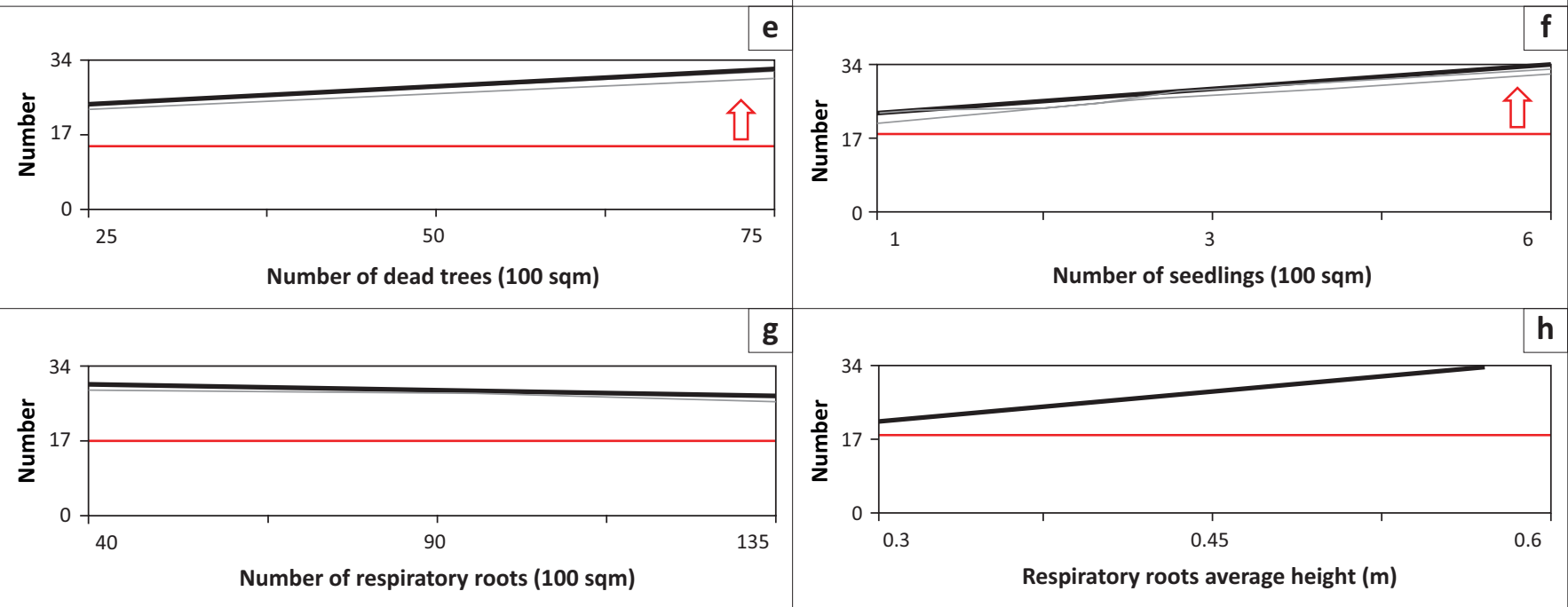

Red arrows $=$ a higher precision of uncertainty.

FIGURE 4: Usfan demographic features sensitivity analysis. (a) Density (100 $\left.\mathrm{m}^{2}\right)$; (b) Cover (\%); (c) Tree height (m); (d) Crown diameter (m); (e) Number of dead trees $\left(100 \mathrm{~m}^{2}\right) ;(\mathrm{f})$ Number of seedlings $\left(100 \mathrm{~m}^{2}\right) ;(\mathrm{g})$ Number of respiratory roots $\left(100 \mathrm{~m}^{2}\right)$ and $(\mathrm{h})$ Average height of respiratory roots $(\mathrm{m})$.

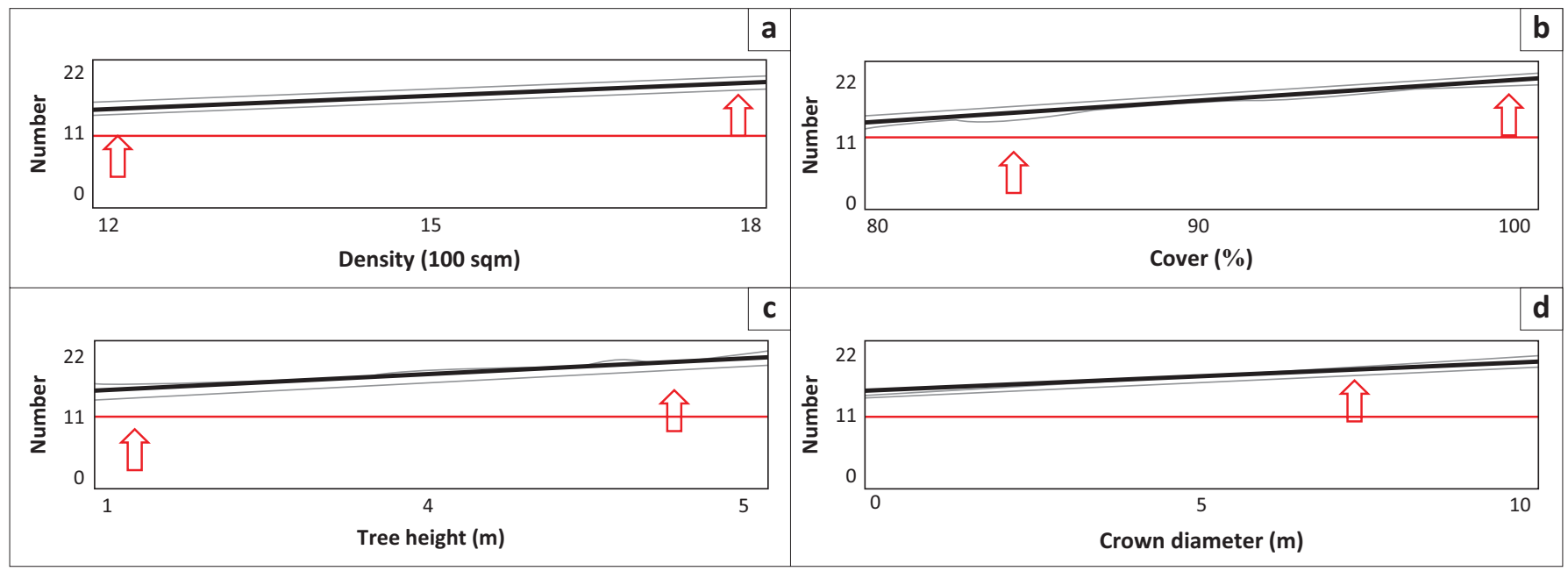

Red arrows = a higher precision of uncertainty.

FIGURE 5: Al Mudhaylif demographic features sensitivity analysis: (a) Density (100 m²); (b) Cover (\%); (c) Tree height (m); (d) Crown diameter (m); (e) Number of dead trees $\left(100 \mathrm{~m}^{2}\right) ;(\mathrm{f})$ Number of seedlings $\left(100 \mathrm{~m}^{2}\right) ;(\mathrm{g})$ Number of respiratory roots $\left(100 \mathrm{~m}^{2}\right)$ and $(\mathrm{h})$ Average height of respiratory roots $(\mathrm{m})$. 


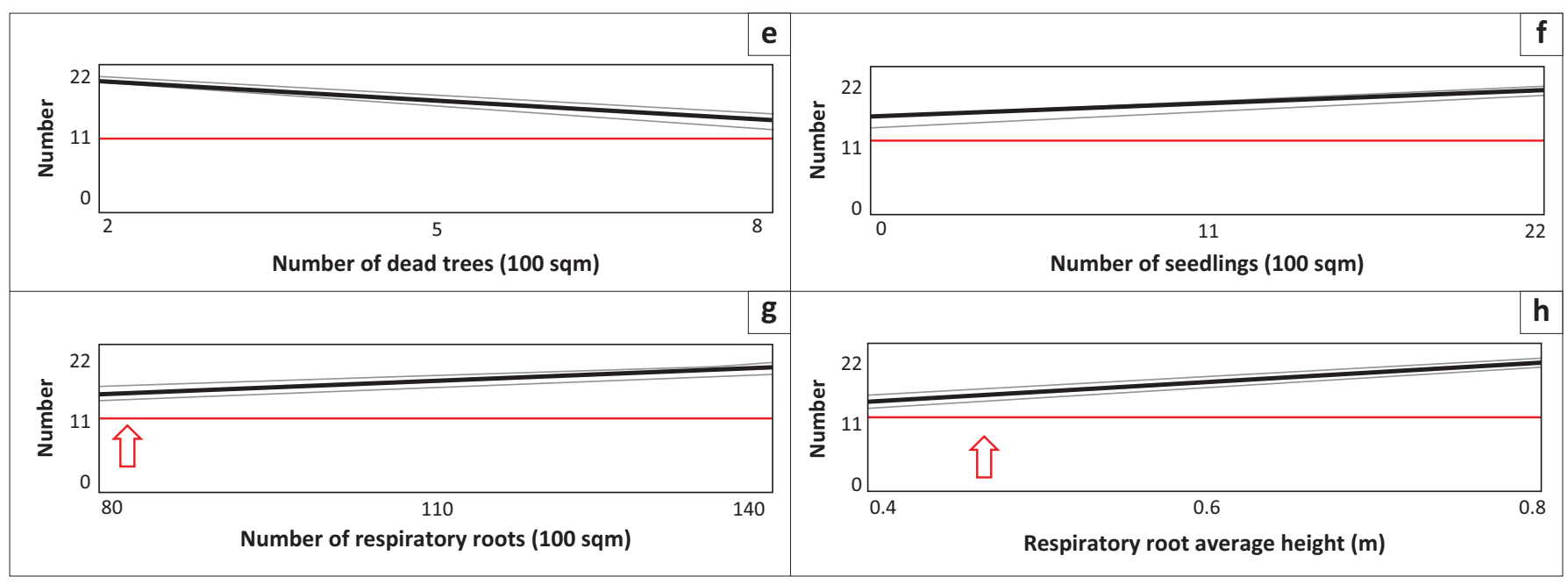

Red arrows = a higher precision of uncertainty.

FIGURE 5 (Continues...): Al Mudhaylif demographic features sensitivity analysis: (a) Density (100 $\left.\mathrm{m}^{2}\right)$; (b) Cover (\%); (c) Tree height (m); (d) Crown diameter ( $\left.\mathrm{m}\right)$; (e) Number of dead trees $\left(100 \mathrm{~m}^{2}\right)$; (f) Number of seedlings $\left(100 \mathrm{~m}^{2}\right)$; (g) Number of respiratory roots $\left(100 \mathrm{~m}^{2}\right)$ and $(\mathrm{h})$ Average height of respiratory roots (m).

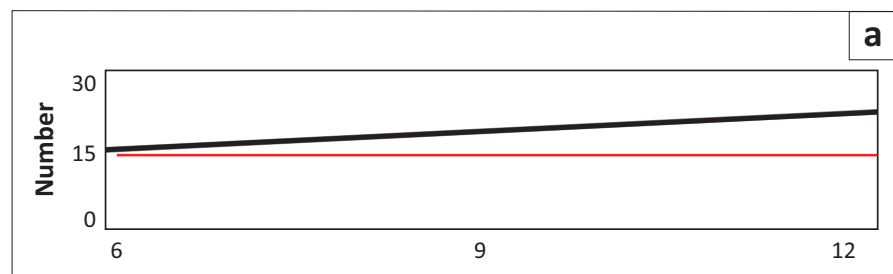

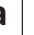

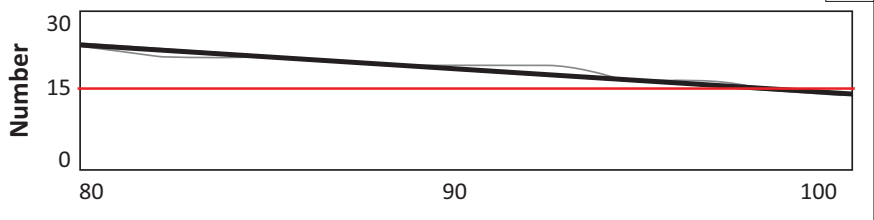

Density (100 sqm)

C

Cover (\%)

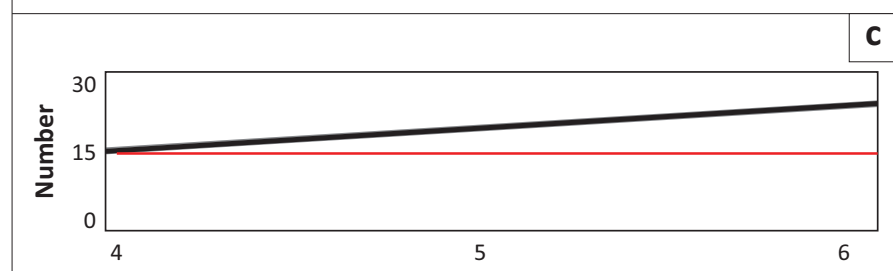

Tree height (m)

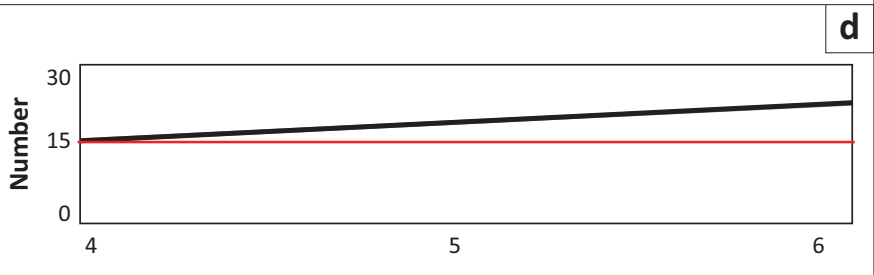

Crown diameter $(\mathrm{m})$

e

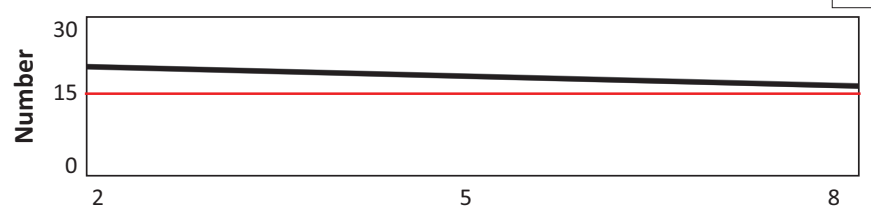

Number of dead trees (100 sqm)

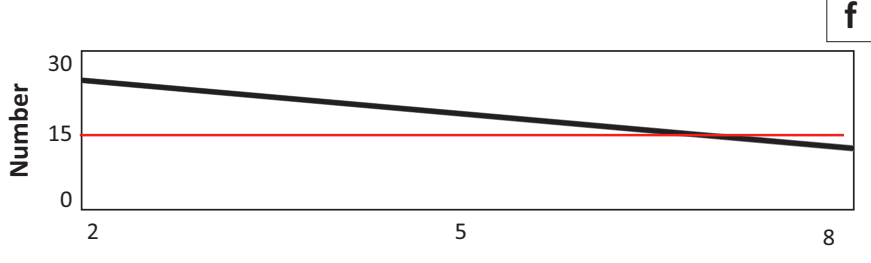

Number of seedlings (100 sqm)

g

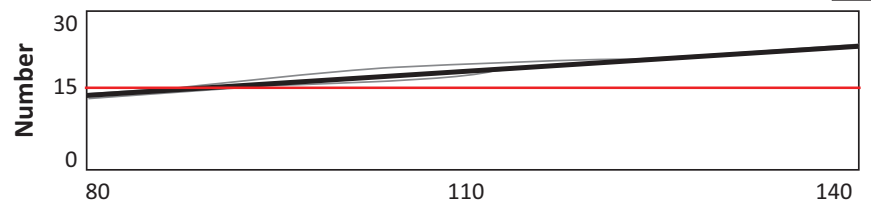

Number of respiratory roots (100 sqm)

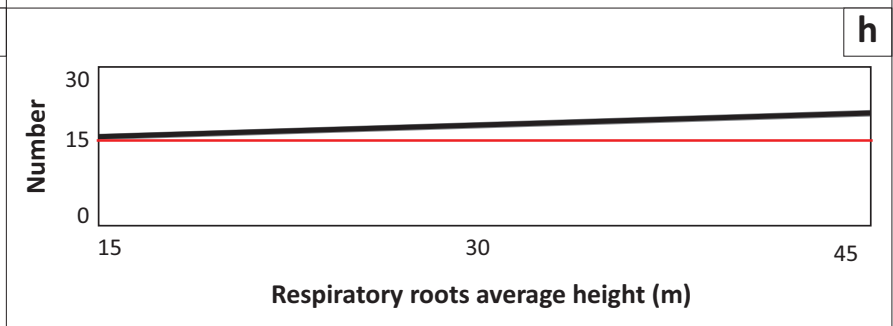

FIGURE 6: Sehat demographic features sensitivity analysis: (a) Density $\left(100 \mathrm{~m}^{2}\right)$; (b) Cover (\%); (c) Tree height ( $\left.\mathrm{m}\right)$; (d) Crown diameter ( $\left.\mathrm{m}\right)$; (e) Number of dead trees $\left(100 \mathrm{~m}^{2}\right)$; (f) Number of seedlings $\left(100 \mathrm{~m}^{2}\right)$; $(\mathrm{g})$ Number of respiratory roots $\left(100 \mathrm{~m}^{2}\right)$ and $(\mathrm{h})$ Average height of respiratory roots $(\mathrm{m})$. 


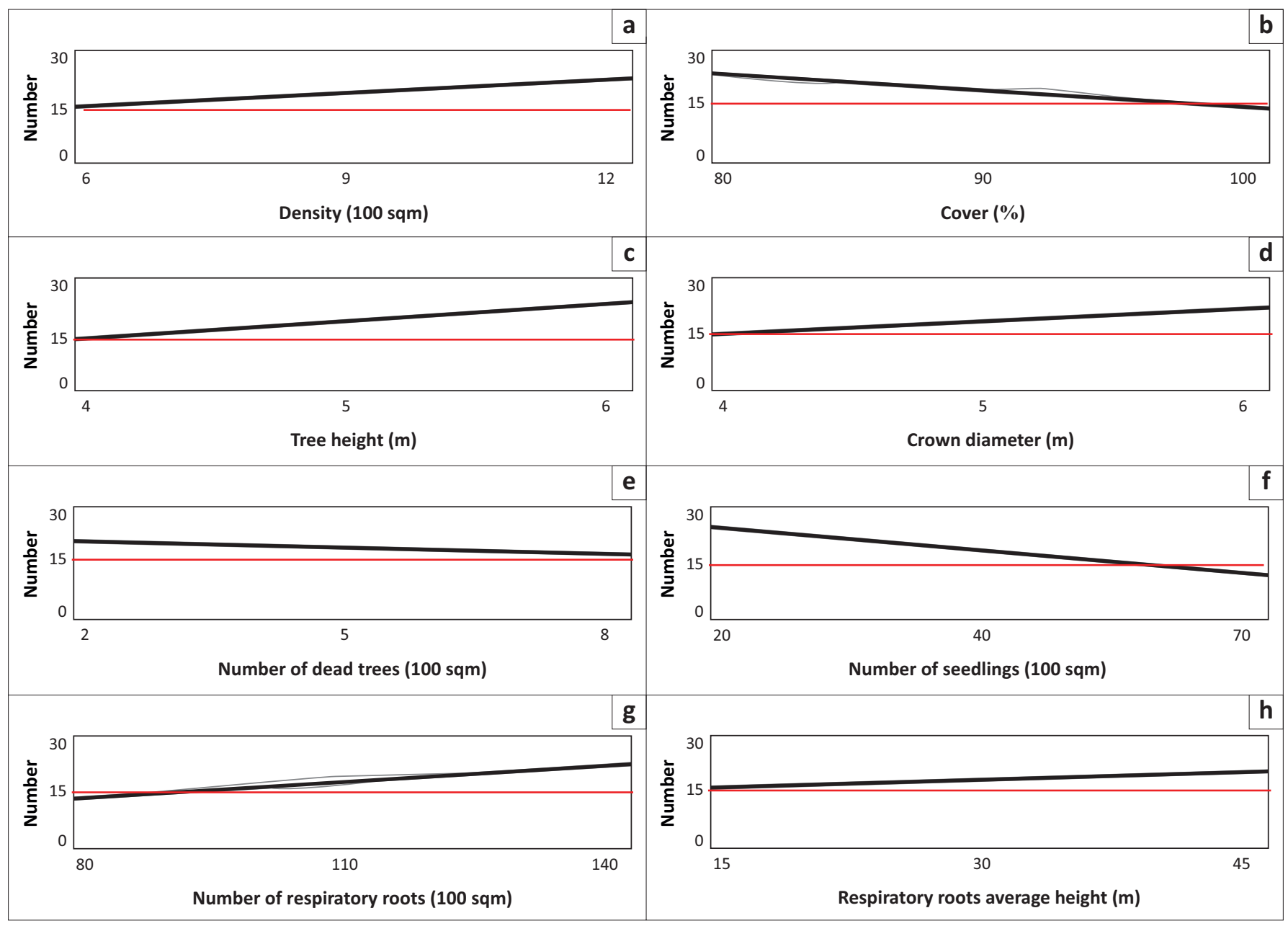

FIGURE 7: Safwa Al Khurais demographic features sensitivity analysis: (a) Density (100 m²); (b) Cover (\%); (c) Tree height (m); (d) Crown diameter (m); (e) Number of dead trees $\left(100 \mathrm{~m}^{2}\right)$; (f) Number of seedlings $\left(100 \mathrm{~m}^{2}\right)$; (g) Number of respiratory roots $\left(100 \mathrm{~m}^{2}\right)$ and $(\mathrm{h})$ Average height of respiratory roots $(\mathrm{m})$.
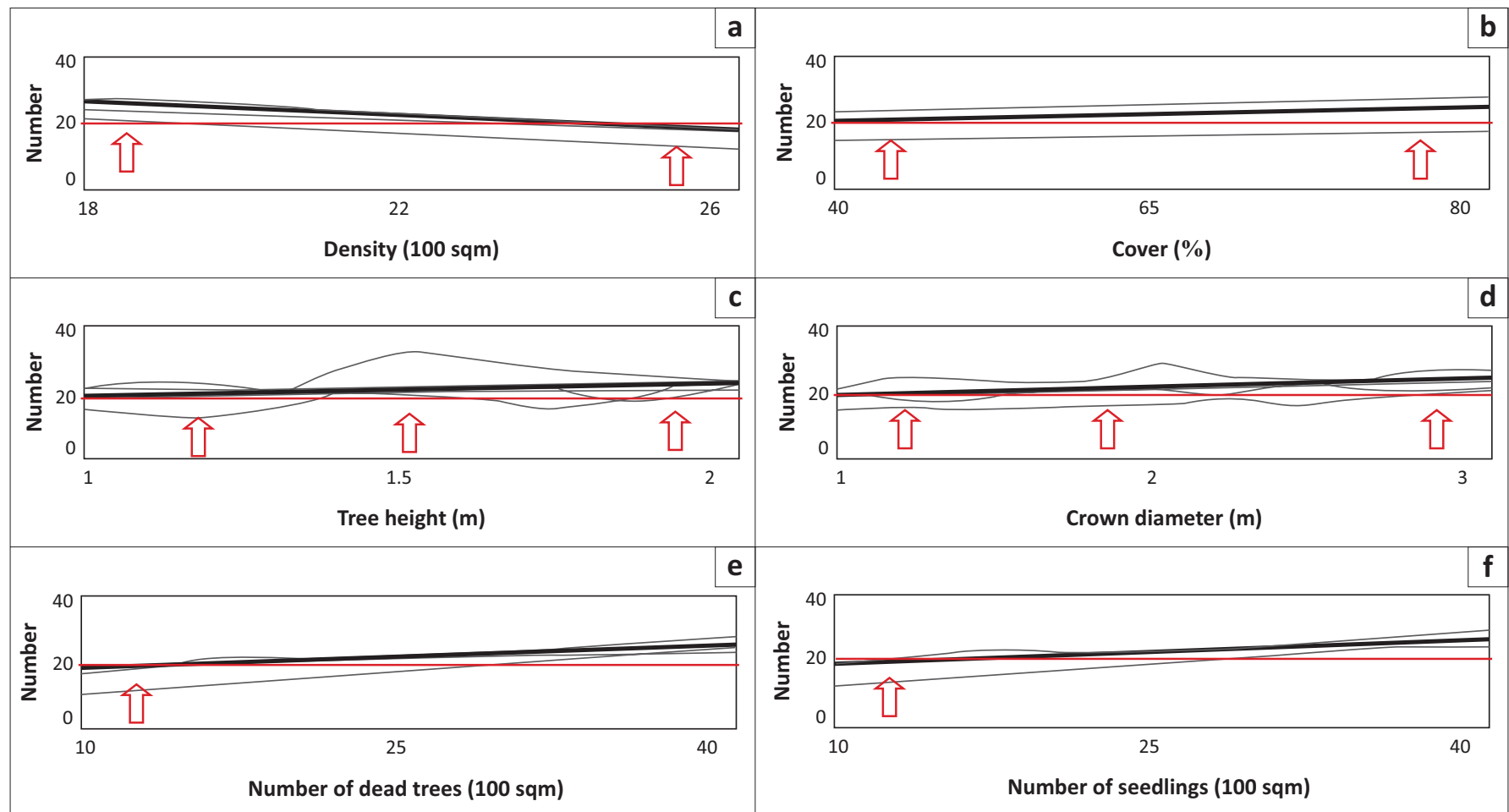

Red arrows = higher precision of uncertainty.

FIGURE 8: Qurum Island demographic features sensitivity analysis (a) Density (100 $\left.\mathrm{m}^{2}\right)$; (b) Cover (\%); (c) Tree height (m); (d) Crown diameter (m); (e) Number of dead trees $\left(100 \mathrm{~m}^{2}\right) ;(\mathrm{f})$ Number of seedlings $\left(100 \mathrm{~m}^{2}\right) ;(\mathrm{g})$ Number of respiratory roots $\left(100 \mathrm{~m}^{2}\right)$ and $(\mathrm{h})$ Average height of respiratory roots $(\mathrm{m})$. 


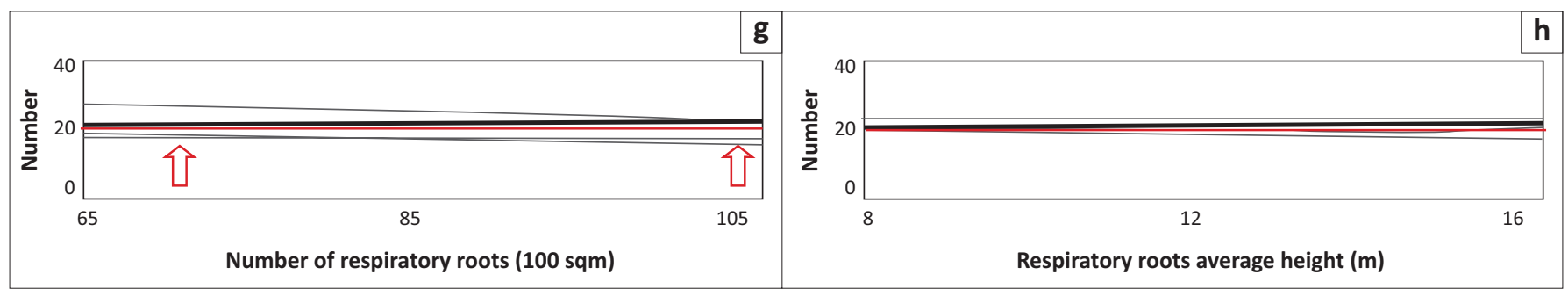

Red arrows = higher precision of uncertainty.

FIGURE 8 (Continues...): Qurum Island demographic features sensitivity analysis (a) Density (100 $\left.\mathrm{m}^{2}\right)$; (b) Cover (\%); (c) Tree height (m); (d) Crown diameter (m); (e) Number of dead trees $\left(100 \mathrm{~m}^{2}\right)$; (f) Number of seedlings $\left(100 \mathrm{~m}^{2}\right)$; (g) Number of respiratory roots $\left(100 \mathrm{~m}^{2}\right)$ and $(\mathrm{h})$ Average height of respiratory roots (m).

\section{Conclusion}

The GSA of the mangroves were measured against eight different demographic features: density, cover, tree height, crown diameter, number of dead trees, number of seedlings, number of respiratory roots and average height of respiratory roots. The GSA delivered quantitative and model-independent sensitivity measures to each of the input factors, and to the input factors collectively, in response to the simulated outputs under consideration.

The results of this study show the model concept to be sufficiently sensitive to represent the behaviour of the natural systems. The sensitivity analysis confirms that demographic features were alternately sensitive to different locations of mangrove stands and that input parameters related directly to the estimated variables derived from the uncertainty analysis. The purpose of implementing a GSA approach was to recognise variance associated with different input measures.

The GSA model is independent of the features of the investigated model. Conducted findings shall mainly be used for better model performance, for example, comparing different demographic features from different locations. Immediate remediation and restoration techniques need to be applied urgently in order to conserve the mangrove stands, especially in the eastern section of the study area.

\section{Acknowledgements}

This work is funded by the project number 11-ENV1756-02, NPST-KACST, Saudi Arabia, entitled 'Conservation and utilisation of mangrove ecosystems in Saudi Arabia: from knowledge to development'.

\section{Competing interests}

The authors declare that they have no financial or personal relationships that may have inappropriately influenced them in writing this article.

\section{Authors' contributions}

A.K.H. (King Saud University) proposed the project idea, participated in all the field work, data analysis and writing of the manuscript. M.E. (King Abdulaziz University) and J.A.B. (King Abdulaziz University) were responsible for the data analysis, and wrote most of the manuscript. M.E.B. (Port Said University) participated in the field work and data collection. A.A-G. (King Abdulaziz University) made conceptual contributions in the writing of the manuscript. A.A.A. (King Saud University) and M.F. (King Saud University) performed some of the experiments.

\section{References}

Elhag, M., 2014, 'Sensitivity analysis assessment of remotely based vegetation indices to improve water resources management', Environment, Development and Sustainability 16(6), 1209-1222. http://dx.doi.org/10.1007/s10668-0149522-0

Hegazy, A.K., 1998, 'Perspectives on phenology, survival and productivity of Avicennia marina in the Qatari coasts, Arabian Gulf', Journal of Arid Environments 40, 417-429.

Holvoet, K., Van Griensven, A., Seuntjens, P. \& Vanrolleghem, P.A., 2005, 'Sensitivity analysis for hydrology and pesticide supply towards the river in SWAT', Physics and Chemistry of the Earth, Parts A/B/C 30, 518-526. http://dx.doi.org/10.1016/j. pce.2005.07.006

Khan, M.A., Kumar, A. \& Muqtadir, A., 2010, 'Distribution of Mangroves along the Red Sea Coast of the Arabian Peninsula: Part 2. The Southern Coast of Western Saudi Arabia', Earth Science India 3(3), 154-162.

Kumar, A., Khan, M.A. \& Muqtadir, A., 2010, 'Distribution of Mangroves along the Red Sea Coast of the Arabian Peninsula: Part 1. The Northern Coast of western Saudi Arabia', Earth Science India 3(1), 28-42.

Mandura, A.S., 1997, 'A mangrove stand under sewage pollution stress: Red Sea', Mangroves and Salt Marshes 1(4), 255-262. http://dx.doi. org/10.1023/A:1009927605517

Mandura, A.S. \& Khafaji, A.K., 1993, 'Human impact on mangrove of Khor Farasan Island, southern Red Sea coast of Saudi Arabia', in H. Leith \& H. Al Masoom (eds.), Towards the rational use of high salinity tolerant plants, vol. 1, pp. 353-261, Kluwer Academic Publishers, Dordrecht.

Petropoulos, G., Wooster, M.J., Carlson, T.N., Kennedy, M.C. \& Scholze, M., 2009, 'A global Bayesian sensitivity analysis of the 1d SimSphere soil-vegetationatmospheric transfer (SVAT) model using Gaussian model emulation' Ecological Modelling 220(19), 2427-2440. http://dx.doi.org/10.1016/j. ecolmodel.2009.06.006

Saltelli, A., 2002, 'Sensitivity analysis for importance assessment', Risk Analysis 22(3), 549-590. http://dx.doi.org/10.1111/0272-4332.00040

Saltelli, A., Chan, K. \& Scott, E.M., 2000, 'Sensitivity analysis', in Wiley series in probability and statistics, p. 467, Wiley, New York.

Saltelli, A., Tarantola, S., Campologno, F. \& Ratto, M., 2004, Sensitivity analysis in practice: A guide to assessing scientific models, p. 217, John Wiley \& Sons, Ltd., Chichester.

Saltelli, A., Tarantola, S. \& Chan, K.P.S., 1999, 'A quantitative modelindependent method for global sensitivity analysis of model output', Technometrics 41(1), 39-56. http://dx.doi.org/10.1080/00401706.1999. 10485594

Schwieger, V., 2004, 'Variance-based sensitivity analysis for model evaluation in engineering surveys', INGEO 2004 and FIG Regional Central and Eastern European Conference on Engineering Surveying, Bratislava, Slovakia, November 11-13, 2004. 